\title{
OS CHINESES ESTÃO CHEGANDO! \\ O QUE FAZER COM MEU MARKETING MIX? \\ O CASO DA RAMADHES \& CIA LTDA.
}

\author{
THE CHINESE ARE COMING! \\ WHAT TO DO WITH MY MARKETING MIX? \\ THE CASE OF RAMADHES E CIA LTDA.
}
Recebido em: 31/07/2013 Aprovado em: 23/09/2013 Avaliado pelo sistema double blind review Editora Científica: Manolita Correia Lima

\author{
JOÃO BATISTASOARES NETO jnetojp@gmail.com \\ ANIELSON BARBOSA DASILVA \\ ANDRÉ GUSTAVO CARVALHO MACHADO \\ UNIVERSIDADE FEDERAL DA PARAÍBA
}

\begin{abstract}
RESUMO
Este caso descreve, com base em fatos reais, a situação de mercado vivenciada pelo Sr. Rodrigo Ramadhes, diretor da Ramadhes \& Cia Ltda., empresa situada no interior de Minas Gerais com mais de 60 anos de história. A empresa é uma das principais produtoras de cintos, mochilas e bolsas da América do Sul. Ao longo dos anos 2000, o grupo Ramadhes \& Cia Ltda. desenvolveu, dentro do seu mix de acessórios, a linha de cintos Madhes, principal produto da empresa e seu sucesso era creditado às políticas do composto de Marketing que conseguiram alinhar o preço, o canal de distribuição e um mix de comunicação a uma concepção de marca pautada em atributos e benefícios funcionais. À luz do Marketing mix, o cenário era favorável para os cintos Madhes, mas o crescimento do рів e dos produtos chineses, entre eles o cinto, incomodava Rodrigo Ramadhes, que chegava a pensar em transferir o parque fabril da Ramadhes \& Cia Ltda. de Minas Gerais para a China em busca de uma maior competitividade. Ele refletia diariamente quais as eventuais implicações desta possível transferência para o composto de Marketing da empresa, diante de uma situação presente favorável, sólida e promissora em termos de mercado.
\end{abstract}

Palavras-Chave: composto de Marketing; posicionamento; marca.

\begin{abstract}
This case, based on real facts, describes the market situation experienced by Rodrigo Ramadhes, the director of Ramadhes \& Cia Ltda., a company based in Minas Gerais that has been operating for more than 60 years. It is one of the leading producers of belts, backpacks and handbags in South America. During the 200os, the company developed the Madhes belt line as part of its range of accessories, which became its main product. Much of this success was credited to the marketing mix policies, which combined the price, distribution channel and a mixture of communication with brand concept based on functional attributes and benefits. According of the marketing mix, the scenario was favorable for the Madhes line, but growing GDP and increasing penetration of Chinese products, including belts, concerned Rodrigo Ramadhes, who began to consider transferring the company's industrial production from Minas Gerais to China in pursuit of a greater competitive edge. He constantly reflected on the possible implications of such a move on the company's marketing mix, despite the current situation being favorable, solid and promising in market terms. Keywords: marketing mix; positioning; brand.
\end{abstract}




\section{INTRODUÇÃO}

Em Janeiro de 2012 o diretor da Ramadhes \& Cia Ltda., Rodrigo Ramadhes, reuniu em um hotel de São Paulo seus executivos e representantes comerciais para analisarem o crescimento da sua empresa, fabricante de cintos, mochilas e bolsas, nos últimos dez anos. O momento era oportuno, pois, na semana seguinte, aconteceria uma das maiores feiras de calçados da América Latina, a Couromoda, onde expositores e lojistas se encontrariam para fecharem novos negócios e conhecerem as principais tendências em cores e modelos de calçados e acessórios.

Todos da Ramadhes \& Cia Ltda. estavam eufóricos com as boas perspectivas de negócios na Couromoda 2012, ficaram entusiasmados quando Rodrigo Ramadhes apresentou os índices de crescimento da fábrica nos últimos dez anos. A cada ano, a Ramadhes \& Cia Ltda. superava entre $20 \%$ e $30 \%$ os seus concorrentes em unidades vendidas e aumentou sua participação no mercado de acessórios para quase ı\% em 20 II.

Mas, qual tinha sido a fórmula do sucesso? Qual o motivo deste rápido crescimento? A resposta era fácil, uma vez que bastava uma simples olhada nas vitrines das principais lojas de calçados e confecções do país para perceber a quantidade de sapatos expostos e vendidos junto com os cintos da linha Madhes. Isso mesmo... o carro chefe da Ramadhes \& Cia Ltda. tinha sido os cintos Madhes, com sua qualidade e variedade de cores, tamanhos e fivelas.

Nada podia ser melhor: os cintos Madhes, principal marca da empresa, apresentava elevados índices de vendas, em função da diversidade de tonalidades e modelagens de acordo com as preferências individuais de cada lojista e um preço bem abaixo da concorrência. Este cenário era perfeito para o crescimento e consolidação da marca Madhes nos próximos anos e nas próximas feiras, como a Couromoda! Era o cenário perfeito, mas não para Rodrigo Ramadhes!

Rodrigo costumava dizer que o sucesso era o primeiro passo para o fracasso. Algo o incomodava, algo ainda não estava encaixado, algo podia melhorar! Para ele, não bastava superar o concorrente, era preciso tirá- 
lo do mercado e para tornar-se competitiva, a empresa teria que ousar e inovar nas estratégias de Marketing e comercialização. Esse sempre foi o seu entendimento de mercado e, por isso, desde 2008 vinha alimentando a ideia de fechar a fábrica da Ramadhes \& Cia Ltda., localizada no interior de Minas Gerais, e transferi-la para a China. Queria reduzir ainda mais o preço do cinto Madhes para ser mais competitivo, o que seria possível apenas por meio de uma estratégia de liderança de custo.

Mas essa decisão não era simples. Não era só o preço mais baixo e outras reflexões pairavam a mente de Rodrigo. Diariamente ele refletia se valeria a pena todo um esforço de transferência da fábrica para outro continente, pois a sua empresa apresentava uma situação já favorável, sólida e promissora em termos de mercado no Brasil. Inquietava-se pensando no risco do mercado consumidor associar a marca do cinto Madhes a um produto chinês e passar a depreciá-lo por isso. Mas o que mais o incomodava eram as incertezas quanto às implicações desta possível transferência nas políticas do composto de Marketing da empresa. A responsabilidade era grande em face de uma possível readequação do Marketing mix! 


\section{O NEGÓCIO DA RAMADHES \& CIA LTDA.}

O Grupo Ramadhes \& Cia Ltda., com mais de 60 anos de história, era um dos principais produtores de cintos, mochilas e bolsas da América do Sul, e um grande produtor de laminados sintéticos (ProPlast) para a indústria da moda, atendendo em todo o Brasil e no Mercosul. A empresa preocupavase com o crescimento sustentável na produção investindo constantemente em inovação tecnológica, tendências de mercado e atualização da equipe de colaboradores.

Para atender a demanda do mercado de acessórios, a Ramadhes \& Cia Ltda. disponibilizava o mix de produto, conforme apresentado no Quadro I.

Quadro I Mix de Produtos da Ramadhes \& Cia Ltda.

\begin{tabular}{|l|}
\hline Cintos masculinos (Linha Print - "popular") \\
\hline Modelo: Casual e Esporte \\
\hline Material: Sintético \\
\hline Cores: preto, marrom, caramelo, verde, whisky, bambu, azul, amarelo, branco, cinza... \\
\hline Carteiras masculinas (Linha Addi) \\
\hline Modelo: Casual e Social \\
\hline Material: Sintético \\
\hline Cores: preto, marrom, caramelo e bambu \\
\hline Cintos e Bolsas Femininas (Linha Venezza) \\
\hline Modelo: Casual e Social \\
\hline Material: Sintético \\
\hline Cores: preto, marrom, caramelo, verde, whisky, bambu, azul, amarelo, branco, cinza... \\
\hline Mochilas (Linha Addi) \\
\hline Modelo: Casual e Esporte \\
\hline Material: Sintético \\
\hline Cores: preto, cinza, marrom, verde \\
\hline Laminado (Linha Proplast) \\
\hline Material: Cabedais e Forros sintéticos \\
\hline Cores: a cor que o cliente desejar \\
\hline
\end{tabular}

Para Rodrigo Ramadhes, diretor e neto do fundador do grupo Ramadhes \& Cia Ltda., todos os produtos da empresa tinham sua importância, mas 
uma linha em especial era o seu xodó: a Madhes. Ela havia sido a primeira marca introduzida no mercado pelo grupo, por meio da comercialização de bolsas para viagens, o que não deu certo. No final da década de I990, Rodrigo ressuscitou a marca no formato de cinto masculino (Quadro 2).

Quadro 2 Linha de cintos Madhes

Cintos masculinos (Madhes)

Modelo: Casual, Social e Esporte

Material: Sintético, lona e Couro

Cores: a cor que o cliente desejar (preto, marrom, bambu, caramelo, verde, azul, etc.)

O diferencial do cinto Madhes era a sua qualidade e a variedade de cores, visto que o grupo Ramadhes \& Cia Ltda. era fabricante do insumo e laminado do produto, o controle da qualidade era rigoroso e a produção das cores individualizada.

Customizar o atendimento... Ah, esse era o maior trunfo dos cintos Madhes! A estrutura flexível e o investimento em pesquisa e desenvolvimento permitiram que a empresa produzisse o cinto Madhes em qualquer tonalidade de cor. Isto agradava aos donos de lojas de calçados, pois estavam sendo comercializados sapatos com cores não muito tradicionais (por exemplo, caramelo, bambu, verde, azul, prata, vermelho, etc.) o que, em muitos casos, dificultava a sua comercialização, gerando altos estoques, pois os consumidores só compravam o sapato se tivesse um cinto na mesma tonalidade.

Certa vez, na Couromoda de 2008, Rodrigo Ramadhes atendeu no stand da empresa um dos principais lojistas de calçados do Brasil:

- Boa tarde seu Vasconcelos, tudo bem? Que prazer em recebê-lo aqui!

- Boa tarde Rodrigo, tudo bem? Tem algum vendedor que possa me atender?

- Sr. Vasconcelos, eu mesmo o atenderei, sem problemas.

— E a comissão dessa venda, vai pra quem? Risos.

- Risos... Não se preocupe, vai para o nosso representante do seu Estado. Aqui o nosso lema é atender e satisfazer bem, sem olhar a quem! Risos. 
—Pois bem Rodrigo... Eu estou com um problemão na minha loja. Comprei alguns milhares de pares de sapato de couro e não consigo vendê-los. É que o diabo do sapato tem uma cor lindíssima, mas é "difícil pra burro" achar um cinto da mesma tonalidade para fazer o kit. E como você sabe, o consumidor só leva o sapato se a cor do cinto for igualzinha!

— E que cor é essa tão difícil? Risos.

- Sei lá... Acho que é uma mistura de caramelo com bambu, meio puxado pra telha... Sei lá... Só sei que é bonita, viu? Peguei até um pra mim, mas estou sem cinto também para combinar... Risos.

- Risos... Pois bem seu Vasconcelos, vamos resolver seu problema. Como o senhor deve saber, temos na Ramadhes \& Cia Ltda. uma estrutura de pesquisa e desenvolvimento de insumos e laminados, o que nos permite desenvolver e projetar qualquer tonalidade de cor para cintos e acessórios. Se o senhor puder me enviar uma amostra desse seu sapato de cor "sei lá" garanto que faço um cinto na mesma corzinha dele bem rapidinho!

—É mesmo?! E vai custar mais caro?

- De forma alguma. Como tudo é feito dentro da nossa fábrica aqui no Brasil, não haverá nenhum custo adicional. Só preciso que o senhor me compre pelo menos 500 unidades do cinto que fechamos a negociação agora. - E quanto tá custando o cinto Madhes? Aumentou de preço?

- Risos... seu Vasconcelos, a única coisa aqui que vai aumentar é o seu faturamento. O senhor vai vender o cinto de couro Madhes em sua loja por apenas $\mathrm{R} \$ 29,90$ e nada mais!

— Quanto?! R\$ 29,90?! Nossa! O menor preço que havia encontrado no seu concorrente foi R\$ 59,90, depois de muito choro. O preço de vocês é imbatível mesmo.

— Essa é a vantagem de quem produz, processa e comercializa o insumo do cinto. Além disso, temos nossa marca própria, a Madhes, tudo feito aqui dentro. E então, negócio fechado?

- Fechadíssimo!

Situações como retratadas neste diálogo provocavam uma satisfação profissional para Rodrigo Ramadhes. Ter uma estrutura e um composto de Marketing capaz de personalizar um cliente, atender a uma demanda 
específica de um mercado e aplicar o conceito de Marketing na sua essência era a razão de ser do grupo Ramadhes \& Cia Ltda. e a realização de um sonho iniciado pelos avôs de Rodrigo na década de 1950. Este era o negócio da Ramadhes \& Cia Ltda.!

Na reunião de Janeiro de 2012, antes da Couromoda, Rodrigo resgatou o diálogo da venda ocorrida em 2008 e mostrou que as estratégias de Marketing direcionadas aos cintos Madhes, ao longo dos últimos anos, levaram esta linha de produto a representar cerca de $40 \%$ do faturamento de todo o grupo Ramadhes \& Cia Ltda. Muito dos 1o\% de participação no mercado de acessórios se creditou ao sucesso de vendas da linha de cintos Madhes. O diretor aproveitou, então, a oportunidade para apresentar o Marketing mix utilizado no desenvolvimento e comercialização do cinto Madhes.

Estava feliz com tudo isso, mas algo o inquietava como empreendedor. Pensava como poderia ousar ainda mais e instalar uma fábrica na China ou, quem sabe, levar apenas a produção dos cintos Madhes para o Oriente. Esta última seria uma ótima opção para baratear a principal linha de produtos da empresa sem arriscar os outros $60 \%$ do faturamento. Seria uma ótima alternativa para competir, não só com as indústrias nacionais, mas também, contra a invasão de cintos chineses no Brasil. Será...? Pensava ele. Quais as contra indicações associadas ao Marketing para tudo isto? 


\section{COMPOSTO DE MARKETING DOS CINTOS MADHES}

A graduação em Administração de empresas e a especialização em Marketing fizeram de Rodrigo Ramadhes um especialista em indústria e comércio varejista. Costumava dizer que não era o diretor da empresa, mas sim o negociador dela. Para ele, antes de gerenciar uma empresa, a pessoa precisava entender do negócio e das ferramentas que faziam parte dele. Por isso, tinha o meticuloso trabalho de sempre estudar o composto de Marketing da Ramadhes \& Cia Ltda.

Entendia que os 4 P's do Marketing eram variáveis controláveis que uma empresa tinha para produzir respostas as demandas do mercado. Teve o cuidado, desde quando assumiu a direção da empresa em 1999, de desenvolver o mix de Marketing da linha de cintos Madhes, na crença de que esta marca seria a sua "menina dos olhos" e o cartão de visita do grupo.

Ele estava certo! A combinação de um bom projeto de produto, uma adequada estratégia de preço, uma política de canal eficiente e um composto de comunicação atuante, eram ferramentas mercadológicas essenciais. Por isso, sua preocupação em delimitar de forma clara o produto, o preço, a praça e a promoção dos cintos Madhes, conforme será retratado a seguir.

\section{PRODUTO}

O cinto era classificado como um bem de compra comparada em relação à quantidade de ofertas existentes no mercado. Assim era o cinto Madhes, só que com uma diferença: era um produto ampliado. A ampliação deste cinto residia na qualidade do material (sintético, lona e couro), nas opções de modelo e fivelas (casual, social e esporte) e na flexibilidade e variedade de cores (fazia-se o cinto na tonalidade que o cliente desejava).

Quando um lojista olhava o catálogo dos cintos Madhes ficava admirado, uma vez que existiam várias opções de compra. Se juntassem os três tipos de materiais, com os três modelos, mais as variedades de cores existentes, era possível montar qualquer tipo de cinto em qualquer tonalidade. Se a cor desejada pelo cliente não estivesse no catálogo, a empresa desenvolvia a partir de uma peça com a tonalidade da cor a ser copiada e desenvolvida 
pela Ramadhes \& Cia Ltda. Estas três variáveis (material, modelagem e cores) geravam para a Madhes um significado de marca relacionado aos atributos (durabilidade, qualidade e variedade) e aos benefícios funcionais (praticidade para montar um cinto ou criar uma cor específica).

Entre os anos de 2008 e 20II, as vitrines das lojas de calçados masculinos eram repletas de kits (sapato e cinto) de diversas tonalidades. O desafio para os fabricantes de cintos era o desenvolvimento de modelos e cores semelhantes aos calçados da moda. Importantes marcas de cintos tentavam acompanhar a tendência de cores e, para isso, terceirizavam sua produção na busca de parceiros especialistas no assunto.

A Ramadhes \& Cia Ltda., além de produtora (às vezes até fabricando para as marcas citadas acima), tinha a sua marca própria (Madhes), o que lhe garantia uma permanente fiscalização, in loco, do processo produtivo e um preço bem abaixo dos concorrentes.

\section{PREÇO}

Rodrigo entendia que todo produto, ao ser precificado, tinha um objetivo de mercado por trás. Para ele, o preço do cinto Madhes tinha que ser competitivo, ao ponto de maximizar a sua participação no mercado e, ao mesmo tempo, gerar uma imagem de qualidade. Costumava afirmar nas reuniões que a perpetuação de uma marca no mercado não se dava apenas pelo aumento do seu market share, mas principalmente pela boa reputação da imagem e qualidade.

O mercado de acessórios masculinos caracterizava-se pela alta elasticidade de preço da demanda, ou seja, qualquer aumento no preço do cinto provocava uma retração no seu consumo. Alguns aspectos relacionados ao consumidor explicavam esta alta elasticidade como a percepção da existência de produtos substitutos, a facilidade de comparação de preço nas lojas e o dispêndio total.

Devido a esta alta elasticidade do mercado, a Ramadhes \& Cia Ltda. procurava, na segunda metade da década de 2000, implantar algumas estratégias de adequação de preço (Quadro 3) para o cinto Madhes. 
Quadro 3 Estratégias de adequação de preço

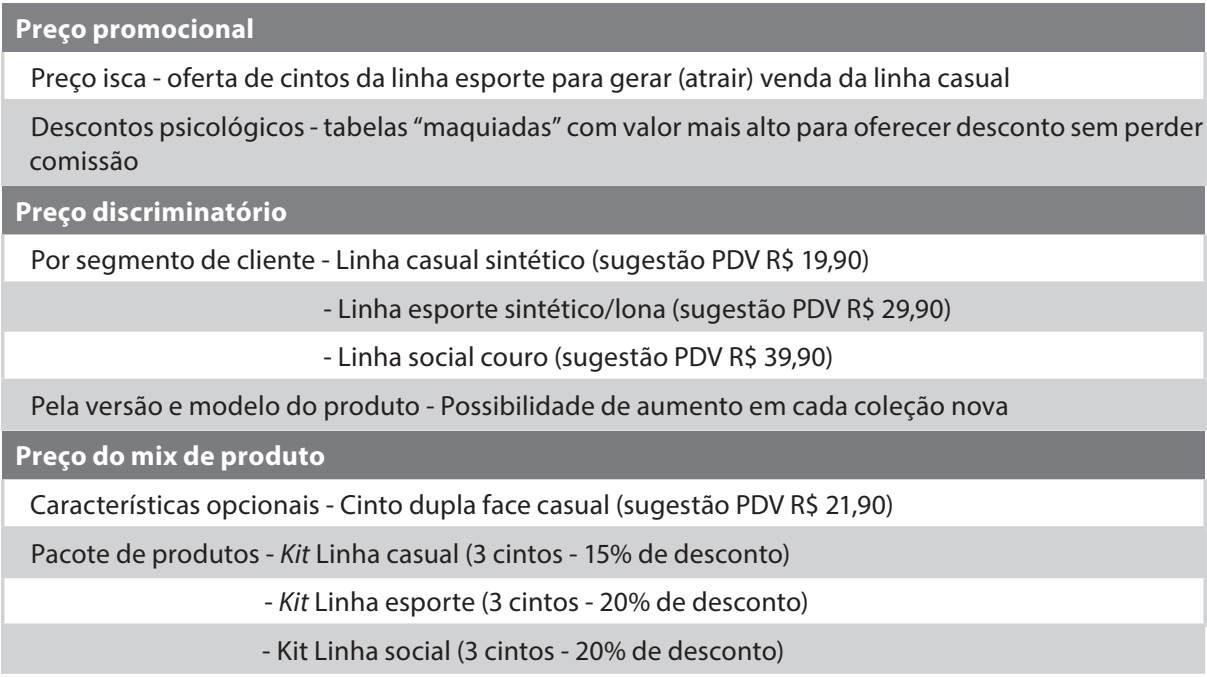

Existia na Ramadhes \& Cia Ltda. uma política de preço bem delimitada na venda do cinto Madhes. Dependendo do tipo de intermediário e volume de compras, os descontos oscilavam entre ı\% a 30\% (Quadro 4).

Quadro 4 Desconto versus Volume de compras do cinto Madhes

Varejo - Até 10\% para compras entre $\mathrm{R} \$ 3.000$ e $\mathrm{R} \$ 5.000$

- Até $15 \%$ para compras acima de $\mathrm{R} \$ 5.000$

Atacado - Até $20 \%$ para compras entre $\mathrm{R} \$ 10.000$ e $\mathrm{R} \$ 20.000$

- Até $30 \%$ para compras acima de $\mathrm{R} \$ 20.000$

As estratégias de adequação e estabelecimento de preço da Ramadhes $\&$ Cia Ltda. na linha de cintos Madhes eram competitivas em relação aos demais concorrentes. O fato de a empresa ser produtora do insumo e ter a sua própria marca de cinto, deixava a marca Madhes em uma situação privilegiada em termos de condições de pagamento e preço médio final no ponto de venda, conforme apresentado na Tabela I. 
Tabela I Condição de Pagamento e Preço médio final no ponto de venda

\begin{tabular}{|lll|}
\hline Marca & Condição de Pagamento para o Lojista & Preço (R\$) médio final no PDV \\
\hline Madhes & 90/120/150 dias & 29,90 \\
\hline Concorrente 1 & 30/60/90 dias & 65,90 \\
\hline Concorrente 2 & 60/90/120 dias & 59,90 \\
\hline Concorrente 3 & $60 / 90 / 120$ dias & 59,90 \\
\hline Concorrente 4 & 60/90/120 dias & 59,90 \\
\hline Concorrente 5 & 30/60/90 dias & 65,90
\end{tabular}

Rodrigo acreditava que uma política de preço adequada deveria estar relacionada a um canal de distribuição diferenciado e devidamente estruturado para atender a demanda de cada região.

\section{PRAÇA}

A Ramadhes \& Cia Ltda. acreditava que o local ou o meio pelo qual o produto é oferecido ao mercado, embora pouco aparente e palpável aos olhos do consumidor, era de fundamental importância para o sucesso do cinto Madhes. Dessa forma, Rodrigo e seus gerentes procuravam entender a melhor forma de administrar como, onde, quando e sob que condições o produto deveria ser colocado nas lojas de acessórios e calçados.

As vendas dos cintos Madhes eram de responsabilidade exclusiva dos Representantes Comerciais da empresa. Eram cerca de 20 representantes devidamente comissionados ( $8 \%$ no faturamento) e alocados em diferentes regiões, uns atendendo aos varejistas e outros aos atacadistas. A eficiência da equipe de vendas permitiu, na década de 2000, que os cintos Madhes fossem distribuídos nas principais lojas de varejo e atacado de calçados, confecções e acessórios do Brasil e em algumas capitais da América do Sul, como Buenos Aires e Montevideo. Grandes magazines, formadoras de opinião, em todo o país, renovavam periodicamente seus estoques de cintos, assim como grandes redes de calçados.

As estratégias de distribuição sugeridas por Rodrigo estavam voltadas para o cumprimento e a política do canal (Quadro 5), e dependiam do modelo do cinto Madhes que seria comercializado. 


\section{Quadro 5 Cumprimento e Política de Canal}

Cumprimento do Canal
Canal indireto curto: Ramadhes \& Cia Ltda. - Varejista - Consumidor Final - Modelo (Casual, Esporte
e Social)
Canal indireto longo: Ramadhes \& Cia Ltda. - Atacadista - Varejista - Consumidor Final - Modelo (Casual)
Política de Canal
Distribuição Seletiva: Intermediários que tinham condições de expor com qualidade e visibilidade os
cintos da linha Casual, Esporte e Social
Distribuição Intensiva: Intermediários que tinham condições de comprar o cinto da linha Casual, inde-
pendente das condições de exposição na loja

\section{PROMOÇÃO}

Existia na Ramadhes \& Cia Ltda. um cuidado na maneira como o cinto Madhes deveria ser promovido, até porque as marcas concorrentes tinham maior expressão e força de mercado em virtude do alto apelo midiático. Para o diretor do grupo, uma divulgação consistente dos atributos e benefícios da marca Madhes implicaria num fortalecimento de longo prazo com os seus clientes. Dessa forma, a propaganda e a promoção de venda (Quadro 6) tinham um importante papel neste objetivo.

Quadro 6 Propaganda versus Promoção de Venda

\begin{tabular}{l} 
Propaganda \\
\hline Tipo: Propaganda de produto \\
Processo de decisão: - Objetivo: informar e persuadir os consumidores \\
- Mensagem: fortalecer os atributos (durabilidade, qualidade e variedade) e bene- \\
fícios funcionais (praticidade para montar um cinto ou criar uma cor) do cinto Madhes \\
- Slogan: Qualidade e estilo do seu jeito \\
- Mídia: Revista Veja e setorial de calçados \\
- Cobertura: Nacional e Internacional (América do Sul) \\
- Frequência: Veja (semanal) e setorial de calçados (trimestral) \\
\hline Promoção de Venda \\
\hline Consumidor Final: - Demonstrações da montagem (fivelas) dos cintos nos pontos de venda \\
- Distribuição de amostras grátis para compradores estratégicos \\
- Participação em feiras do setor como a Couromoda e Francal
\end{tabular}


Promoção de Venda

Varejo: - Descontos progressivos (10\% a $30 \%)$ para o aumento no volume das compras

- Serviços de Merchandising nos pontos de venda (Expositores de cintos e banners)

- Reposição, arrumação e troca periódica dos expositores de cintos e banners

- Prêmio para os vendedores do ponto de venda: A cada dez cintos vendidos ele ganhava um

Outra ferramenta do composto de comunicação utilizada na divulgação do cinto Madhes era a Venda Pessoal. Constantemente, nas reuniões da empresa, Rodrigo se considerava, acima de tudo, um vendedor. Tinha convicção de que a venda pessoal era um conjunto de atividades realizadas com o propósito de informar, motivar e persuadir o cliente a adquirir um cinto. Dividia esta responsabilidade com a equipe e mesmo sendo o diretor da empresa fazia questão de vender pessoalmente para dois dos maiores clientes do varejo de confecção do país. Carregava o mostruário e catálogo do cinto Madhes debaixo do braço e atendia estes dois grandes varejistas mensalmente. Para não gerar discórdia ou qualquer mal-estar, não fazia questão da comissão (repassava-a para o representante do Estado), queria apenas sentir o mercado, analisar a aceitação do seu cinto nos PDV (ponto de venda), pesquisar preços e exposição dos concorrentes, conversar com os vendedores da loja.

O diretor da empresa se realizava como vendedor e por isso valorizava os vendedores da empresa. Gerenciava e motivava sua equipe de representantes como nenhuma outra empresa do setor. A comissão sobre as vendas era a mais alta do mercado (8\%), o pagamento era feito integralmente no faturamento do pedido e anualmente os melhores vendedores ganhavam prêmios como viagens e comissões extras. Em contrapartida, exigia profissionalismo, dedicação, responsabilidade, estudo do produto e do mercado, e, especialmente, capacidade de planejamento e previsão de vendas.

Além da equipe de vendas, o grupo Ramadhes \& Cia Ltda. disponibilizava, 24 horas por dia, um serviço de atendimento ao cliente (SAC). Os e-mails e telefones de todos os Representantes Comerciais estavam disponíveis no sítio da empresa, assim como a ouvidoria para receber as reclamações e sugestões do mercado. 


\section{O MERCADO CHINÊS}

A reunião em janeiro de 2012 , na véspera da Couromoda, foi animadora. Os números da empresa apresentados pelo diretor, Rodrigo Ramadhes, eram motivadores: o crescimento nas vendas (20\% a $30 \%)$, o aumento na participação no mercado (I0\% do market share), a satisfação dos clientes com a customização do produto, como no caso do Sr. Vasconcelos, eram indícios de que a linha de cintos Madhes, enquanto carro-chefe da empresa, estava no caminho certo. $\mathrm{O}$ sucesso do produto era creditado às políticas do composto de Marketing que, segundo o próprio Rodrigo, conseguiram alinhar o preço, o canal de distribuição e um mix de comunicação a uma concepção de marca pautada em atributos (durabilidade, qualidade e variedade) e em benefícios funcionais (praticidade na montagem e escolha da cor do cinto). Diferenciais que só a Ramadhes \& Cia Ltda. conseguiam, pois além de produtores do insumo, tinham sua própria marca.

Mesmo com todo este cenário favorável e promissor, Rodrigo estava incomodado, inquieto. Seu temor tinha nome: China! Os jornais da década de 2000 noticiavam a representatividade do PIB chinês (Gráfico I), o crescimento exponencial das empresas chinesas e o quão competitivas em termos de preço elas eram.

Gráfico I Comparação entre o Рів do Brasil e de países desenvolvidos e emergentes - resultado em percentual

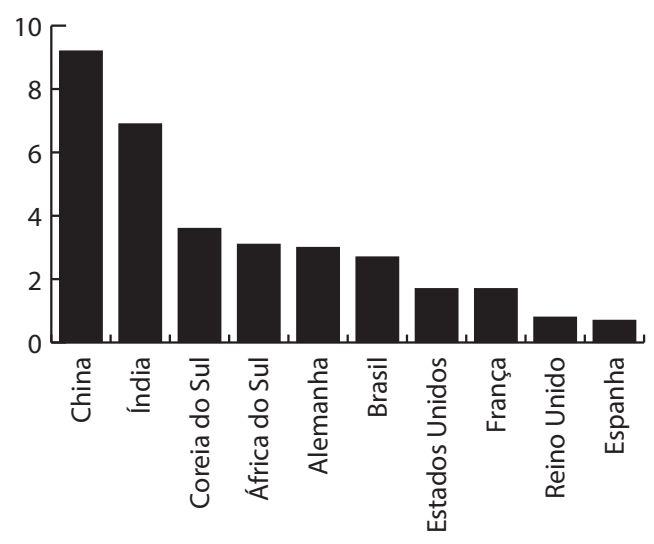

Fonte: Falcão (20I2). 
A indústria e a construção representavam cerca de $50 \%$ do PIB chinês, Além disso, aproximadamente $8 \%$ de todos os produtos manufaturados do mundo eram fabricados neste país. A representatividade das empresas chinesas no segmento de acessórios, vestuários e calçados era representativa e passou a chamar atenção do grupo Ramadhes \& Cia Ltda. Diversas empresas chinesas exportavam cintos para o mercado brasileiro a preços bem abaixo dos praticados aqui. Muitos desses cintos, e até outros manufaturados eram de baixa qualidade e de conhecimento das próprias autoridades chinesas, conforme informações divulgadas nos portais eletrônicos brasileiros em 2012 e 2007. O site "O País Online" estampava "China reconhece fraca qualidade de produtos que exporta para o mundo" е о "ввС Brasil.com" acrescentava "produtos chineses enfrentam crise de credibilidade". Mas, mesmo assim, muitos lojistas compravam estes produtos na expectativa de maximização do lucro e contenção de gastos.

Aos poucos estas mercadorias entravam fortemente no mercado formal e informal brasileiro, o que provocou a falência de diversas fábricas de acessórios e calçados, especialmente no sudeste do país.

Rodrigo Ramadhes organizou e liderou, em 2009, uma comitiva, representando os fabricantes de calçados e acessórios do Brasil, para pressionar o governo e o congresso nacional a desenvolverem estratégias políticas e tarifárias para contenção destes produtos chineses. Sem sucesso!

\section{O DILEMA}

A preocupação de Rodrigo não era com a competição entre as empresas nacionais, mas sim, com o gigante oriental. Embora o grupo Ramadhes estivesse, atualmente, com um Marketing mix ajustado e ótimo desempenho nas vendas dos seus cintos, a empresa poderia perder espaço para os produtos chineses com seus preços mais baixos e a oferta de margens de lucros maiores para os lojistas.

Neste contexto, a transferência da produção para a China (seja pela montagem de um novo parque fabril seja apenas pela terceirização da produção), apesar de ser uma alternativa, ainda gerava incertezas quanto à imagem da marca caso os consumidores a associassem a produtos de 
baixa qualidade. Mais do que isto, indagava-se sobre as implicações práticas desta possível transferência para o composto de Marketing do cinto Madhes. Por outro lado, caso resolvesse continuar com sua produção no Brasil e enfrentar uma realidade cada vez mais desafiadora, teria que realizar transformações radicais nas políticas empreendidas no Marketing mix para lidar com os novos entrantes. 
NOTAS DE ENSINO

\section{OBJETIVOS EDUCACIONAIS}

O caso aborda como temática principal o composto de Marketing. Apresenta como teorias relevantes às decisões do marketing mix; imagem da marca; política de preço; composto de comunicação; estratégia de venda; ética em Marketing; posicionamento de mercado.

Recomenda-se sua aplicação nas disciplinas de Introdução ao Marketing (em nível de graduação em Administração) ou Marketing, tendo como objetivo desenvolver nos discentes competências voltadas a interpretação dos conceitos e variáveis do Marketing mix e compreensão da inter-relação entre elas. A interdisciplinaridade do caso envolve as áreas de Marketing, vendas, comportamento do consumidor, ética e produção. Além disso o caso enfatiza a decisão de levar a produção para a China ou não, enaltecendo a questão da readequação do Marketing mix.

\section{QUESTÕES PARA DISCUSSÃO}

1 Ciente de que uma das decisões do produto é a marca, analise quais os significados de marca que o cinto Madhes poderá explorar no mercado brasileiro caso a Ramadhes \& Cia Ltda. se instale na China.

2 Caso o cinto seja produzido na China, analise as estratégias de adequações de preços que a empresa poderá utilizar no mercado brasileiro para a linha Madhes.

3 Avalie quais os tipos e a política de canal que melhor se adequa a possível nova realidade da empresa na China. Cite vantagens e desvantagens.

4 Detalhe as ações do composto de comunicação necessárias para que a empresa continue crescendo no mercado de acessórios, caso ela opte por se instalar na China.

5 Caso a decisão fosse não produzir na China, como poderia ser readequado o Marketing mix para competir com os produtos Chineses? 


\section{TÓPICOS PEDAGÓGICOS}

Sugere-se, para uma aplicação mais adequada do caso, que os alunos sejam divididos em grupos de cinco; que estudem o caso previamente, com a possibilidade de analisar as variáveis e opções necessárias para a tomada de decisão.

Ciente de que os alunos já fizeram a leitura prévia do caso e considerando o tempo de uma aula em th e $40 \mathrm{~min}$, deve-se destinar Io' para uma releitura do caso, 25' para uma discussão no pequeno grupo, 45’ para uma discussão no grande grupo e 20 ' para o fechamento do caso.

É possível, inicialmente, observar certa dificuldade do aluno em interrelacionar as variáveis do mix de Marketing, em função do pouco estímulo interpretativo, crítico e integrado de conteúdos presentes no ensino superior brasileiro. Superada esta etapa, espera-se que os alunos de administração ou Marketing vivenciem os dilemas e inquietudes do protagonista do caso, participando das discussões ao longo do processo decisório do Marketing mix da empresa, conjecturando cenários do mercado consumidor de acessórios e propondo soluções e estratégias para os problemas do composto de Marketing. Acredita-se que a participação ativa nas discussões dos pequenos e grandes grupos, além de um relatório individual de cada grupo no final da aula com as soluções para as questões, devam ser os critérios de avaliação discentes.

\section{ANÁLISE DO CASO E CONEXÃO COM A LITERATURA}

O debate deste caso deve ser iniciado com o entendimento do conceito e ambiente de Marketing. Para Kotler e Keller (2006) existem diferenças entre o marketing social, voltado para a sociedade, e o Marketing gerencial, preocupado em entender o consumidor e vender produtos adequados às suas necessidades.

Dentro do escopo gerencial do Marketing, entende-se que as ferramentas do seu composto são variáveis necessárias para produzir as respostas que o mercado-alvo deseja. Mais que isso, o conceito de Marketing mix prevê uma inter-relação entre o produto, o preço, a praça e a promoção, ou 
seja, qualquer alteração em uma destas variáveis pode gerar impacto nas demais. Esta inter-relação entre os 4 P's é retratada nos dilemas vividos pelo protagonista deste caso.

\section{COMPOSTO DE MARKETING}

\section{Produto}

Para Kotler e Keller (2006) o produto é algo que pode ser oferecido a um mercado, para sua apreciação, aquisição, uso ou consumo, que pode satisfazer um desejo ou uma necessidade; inclui objetos físicos, serviços, personalidades, lugares, organizações e ideias. Importante que uma empresa reconheça em que nível de produto está trabalhando e direcione seus esforços para sua ampliação, ou seja, ofereça produtos que excedam as expectativas dos clientes.

Uma das decisões de produtos mais pontuais refere-se à marca, conforme aponta Basta et al. (2003). A marca quando bem trabalhada pode representar um ativo da organização, valorizar os produtos, conquistar a lealdade dos mercados e gerar significados nos consumidores. Estes significados são percepções que os consumidores têm das marcas quando as enxergam, por exemplo: Um consumidor pode olhar para uma marca e associá-la a algo valoroso, a uma personalidade, a uma cultura, a um tipo de usuário, a um atributo ou a um benefício.

Na Questão 1 deve-se tratar dos significados de marca relacionados aos atributos como: durabilidade, qualidade e variedade, e aos benefícios funcionais como a praticidade na montagem da cor do cinto, especialmente porque a indústria de acessórios vem desenvolvendo produtos em nível ampliado.

\section{Preço}

Preço é o valor agregado que justifica a troca. Para Basta et al. (2003) a transferência de posse de um produto é planejada e adequada por esse elemento. Fundamenta-se que uma boa estratégia de preço deve integrar o valor percebido, o custo e o benefício gerado (KOTLER; KELLER, 2006). Além disso, dois aspectos devem ser contemplados no estudo do preço: 
A O processo de estabelecimento do preço: cujo foco é no objetivo do preço; na determinação da demanda; na análise dos custos, preços e ofertas dos concorrentes; na seleção de um método de determinação de preços; e na influência dos outros elementos do Marketing mix na seleção do preço final.

B Processo de adequação do preço: análise das estratégias do preço geográfico; preço com descontos; preço promocional; preço discriminatório e preço pelo mix de produtos.

$\mathrm{Na}$ Questão 2, pode-se explorar as estratégias de adequação voltadas para o preço promocional (por exemplo, preço isca e o desconto psicológico), o preço discriminatório (por exemplo, segmento de cliente e versão do produto) e o preço pelo mix de produto (por exemplo, linha de produtos e pacotes de produto).

\section{Praça}

A Praça é o local ou o meio pelo qual o produto é oferecido. Fundamentase, com base em Basta et al. (2003) e Kotler e Keller (2006), que o gestor de Marketing deve planejar e administrar onde, como, quando e sob que condições o produto será colocado no mercado. Entre as suas decisões, estão a escolha do número e tipos de intermediários (varejo, atacado e distribuidor), o tipo de canal (direto ou indireto) e a política de canal (exclusiva, seletiva ou intensiva)

$\mathrm{Na}$ Questão 3, sugere-se que seja discutida a utilização apenas de varejistas, o que caracterizaria um canal indireto. Quanto à política de canal, buscando resgatar a imagem de produto de qualidade, possivelmente maculada pela associação com um produto chinês, pode-se trabalhar com a política exclusiva (vender onde se controla a venda) ou seletiva (vender onde se vende melhor).

\section{Promoção}

Observa-se que promover os produtos, serviços, benefícios, valores e marcas de uma empresa, objetivando fortalecer o relacionamento de longo prazo com os seus clientes é uma atividade pertinente à área de Marketing. $\mathrm{O}$ 
processo de divulgação entre a organização e o mercado, segundo Basta et al. (2003) e Lima et al. (2003) se dá por meio das cinco ferramentas do composto de comunicação: propaganda, promoção de vendas, relações públicas, venda pessoal e SAC. Os autores apontam vantagens e desvantagens na utilização de cada uma delas, e sugerem, assim como Kotler e Keller (2006), que sejam analisados, antes da escolha da ferramenta, o objetivo, a mensagem, o mercado e o público-alvo.

Encaminha-se a Questão 4 para a utilização de quatro variáveis do composto de comunicação:

A a) Propaganda (propaganda de produto ou institucional veiculando mensagens informativas e persuasivas quanto à imagem e qualidade do produto);

в b) Promoção de vendas: inicialmente com foco no varejista para reforçar a imagem de qualidade dos cintos Madhes, realizando campanhas de incentivo aos vendedores das lojas. Posteriormente o foco no consumidor final, por meio de demonstrações nos pontos de venda e distribuições de amostras grátis.

C c) Relações públicas: o público interno da organização precisa entender os novos horizontes e perspectivas da empresa que sua possível ida para a China pode trazer. Sugere-se que a gestão da comunicação interna publique notícias sobre os acontecimentos.

D d) Venda pessoal: espera-se uma estrutura capaz de treinar os representantes comerciais para contornar as adversidades advindas da possível associação dos cintos Madhes com o produto chinês da baixa qualidade. O representante comercial é peça importante nas ações de promoção de vendas com foco tanto no varejo quanto no consumidor final. 


\section{READEQUAÇÃO DO MARKETING MIX}

O projeto do produto, a definição de preço, as decisões sobre os canais de distribuição e as estratégias de promoção dependem do posicionamento que a organização deseja ter no mercado, segundo Hooley, Piercy e Nicolaud (20II). Dessa forma a readequação do Marketing mix pode ser trabalhada por meio do novo posicionamento no mercado em função da maneira como o produto será definido pelos consumidores no que diz respeito aos atributos importantes. É o lugar que o produto ocupa na mente dos consumidores em relação aos produtos concorrentes.

Entende-se que a Questão 5 contempla a readequação do Marketing mix a partir das estratégias de posicionamento. A partir das estratégias de adequação de preços e das variáveis do composto de comunicação adotados para competir com os baixos preços dos produtos chineses, a empresa pode explorar o modelo AIDA - A - Attention/Awareness (Atenção/ Consciência), I - Interest (Interesse), D - Desire (Desejo) e A - Action (Ação) na estruturação da mensagem e slogan do cinto Madhes e desenvolver estratégias de posicionamento pelo atributo/ benefício (durabilidade, qualidade, variedade e praticidade na montagem da cor do cinto). Podese utilizar também, o posicionamento pelo concorrente dependendo das ações de Marketing que ele adote, ou até mesmo em retaliação a alguma mensagem mais provocativa 


\section{FONTES DE DADOS}

Este caso é baseado em fatos reais de uma fábrica de acessórios brasileira, que há mais de 60 anos produz cintos, mochilas e bolsas para a América do Sul. As situações descritas são fieis à realidade investigada. Os dados secundários foram obtidos mediante pesquisas bibliográficas sobre a empresa, concorrentes e o mercado em que atuava. Na coleta dos dados primários, foram utilizadas técnicas de observação e entrevistas, ao longo do segundo semestre de 2012 e início de 20I3, com ex-funcionários da organização. Em função da privacidade e da não autorização da divulgação dos nomes, tanto a empresa quanto os personagens tiveram seus nomes alterados. 


\section{REFERÊNCIAS E BIBLIOGRAFIA DE APOIO RECOMENDADA}

BASTA, D.; MARCHESINI, F.R.A.; OLIVEIRA, J.A.F.; SÁ, L.C. Fundamentos de Marketing. Rio de Janeiro: FGV, 2003.

CHINA reconhece fraca qualidade de produtos que exporta para o mundo. O pais online. São Paulo, 13/12/2012. Disponível em: <http://www.opais.co.mz/index.php/ economia/38-economia/23360-china-reconhece-fraca-qualidade-de-produtos-queexporta-para-o-mundo.html> Acesso em: 12/05/2013.

DIAS, S.R. Gestão de Marketing. São Paulo: Saraiva, 2003.

FALCÃO, C. Brasil Cresce 2,7\% em 2001 e vira a $6^{\text {a }}$ economia do mundo. Portal IG. Rio de Janeiro, 06/03/2012. Disponível em: <http://economia.ig.com.br/economiabrasileira-cresce-27-em-2011/n1597665838398.html> Acesso em: 12/05/2013

HOOLEY, G.; PIERCY, N.; NICOLAUD, B. Estratégia de Marketing e posicionamento competitivo. 4.ed. São Paulo: Pearson Prentice Hall, 2011.

KOTLER, P.; KELLER, K.L. Administração de Marketing. 12.ed. São Paulo: Pearson Prentice Hall, 2006.

LIMA, M.F.; SAPIRO, A.; VILHENA, J.B.; GANGANA, M. Gestão de Marketing. Rio de Janeiro: FGV, 2003.

RIES, A.; TROUT, J. Posicionamento: a batalha por sua mente. São Paulo: Pearson Makron Books, 2002.

URDAN, F.T.; URDAN, A.T. Gestão do composto de Marketing. São Paulo: Atlas, 2006.

WENZEL, M. Produtos chineses enfrentam crise de credibilidade. BBC Brasil.com. São Paulo, 06/07/2007. Disponível em: <http://www.bbc.co.uk/portuguese/reporterbbc/ story/2007/07/070706_marinaprodutoschinafp.shtml> Acesso em:12/05/2013. 


\section{DADOS DOS AUTORES}

\section{JOÃO BATISTA SOARES NETO^ ${ }^{\star}$ netojp@gmail.com} Mestre em Administração pela UFRN

Instituição de vinculação: Universidade Federal da Paraíba

João Pessoa/PB - Brasil

Áreas de interesse em pesquisa: Marketing.

* Universidade Federal da Paraíba /PPGA Cidade Universitária-Castelo Branco

João Pessoa/PB 58051-900

\section{ANIELSON BARBOSA DA SILVA anielson@pq.cnpq.br}

\section{Doutor em Engenharia de Produção pela UFSC}

Instituição de vinculação: Universidade Federal da Paraíba

João Pessoa/PB - Brasil

Áreas de interesse em pesquisa: Aprendizagem Gerencial e Organizacional, Gestão por Competências, Comportamento Organizacional e Gestão Pública.

\section{ANDRÉ GUSTAVO CARVALHO MACHADO agcmachado@gmail.com}

\section{Doutor em Administração pela UFPE}

Instituição de vinculação: Universidade Federal da Paraíba

João Pessoa/PB - Brasil

Áreas de interesse em pesquisa: Estratégia. 